\title{
Polyphenolic Extract from Sambucus ebulus L. Leaves Free and Loaded into Lipid Vesicles
}

\author{
Ramona-Daniela Păvăloiu 1,2, Fawzia Sha'at ${ }^{1,2}\left(\mathbb{D}\right.$, Corina Bubueanu ${ }^{1}$, Mihaela Deaconu ${ }^{2}$,

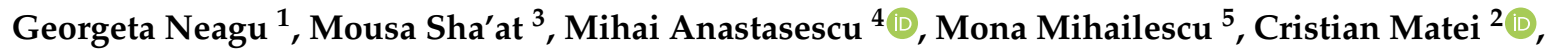 \\ Gheorghe Nechifor ${ }^{2}$ and Daniela Berger $2, *($ C) \\ 1 National Institute for Chemical-Pharmaceutical Research and Development-ICCF Bucharest, \\ Vitan Avenue 112, 031299 Bucharest, Romania; pavaloiu_daniella@yahoo.com (R.-D.P.).; \\ fawzya.shaat@gmail.com (F.S.); corina.bubueanu@yahoo.com (C.B.); getabios@yahoo.com (G.N.) \\ 2 Faculty of Applied Chemistry and Materials Science, University "Politehnica" of Bucharest, 1-7 Gheorghe \\ Polizu St., 011061 Bucharest, Romania; mihaela_deaconu@yahoo.com (M.D.); cristian.matei@upb.ro (C.M.); \\ doru.nechifor@yahoo.com (G.N.) \\ 3 Faculty of Pharmacy, University of Medicine and Pharmacy Grigore T. Popa, Iasi, Universitatii Avenue, 16, \\ 700115 Iasi, Romania; mousa.shaat1@gmail.com \\ 4 "Ilie Murgulescu" Institute of Physical-Chemistry, Romanian Academy, Splaiul Independentei no. 202, \\ 060021 Bucharest, Romania; manastasescu@icf.ro \\ 5 Physics Department, University "Politehnica" of Bucharest, Splaiul Independetei no 313, 060042 Bucharest, \\ Romania; mona.mihailescu@yahoo.com \\ * Correspondence: daniela.berger@upb.ro
}

Received: 8 November 2019; Accepted: 21 December 2019; Published: 25 December 2019

check for updates

\begin{abstract}
The paper deals with the preparation and characterisation of hydroalcoholic polyphenolic extract from Sambucus ebulus (SE) leaves that was further loaded into three-types of lipid vesicles: liposomes, transfersomes, and ethosomes, to improve its bioavailability and achieve an optimum pharmacological effect. For Sambucus ebulus L.-loaded lipid vesicles, the entrapment efficiency, particle size, polydispersity index and stability were determined. All prepared lipid vesicles showed a good entrapment efficiency, in the range of $75-85 \%$, nanometric size, low polydispersity indexes, and good stability over three months at $4{ }^{\circ} \mathrm{C}$. The in vitro polyphenols released from lipid vehicles demonstrated slower kinetics when compared to the free extract dissolution in phosphate buffer solution at $\mathrm{pH}$ 7.4. Either free SE extract or SE extract loaded into lipid vesicles demonstrated a cytoprotective effect, even at low concentration, $5 \mathrm{ug} / \mathrm{mL}$, against hydrogen peroxide-induced toxicity on L-929 mouse fibroblasts' cell lines. However, the cytoprotective effect depended on the time of the cells pre-treatment with SE extract before exposure to a hydrogen peroxide solution of $50 \mathrm{mM}$ concentration, requiring at least $12 \mathrm{~h}$ of pre-treatment with polyphenols with radical scavenging capacity.
\end{abstract}

Keywords: Sambucus ebulus; lipid vesicles; polyphenols; cytoprotective effect

\section{Introduction}

Sambucus ebulus L. (fam. Adoxaceae) (SE) is a herbaceous, perennial plant, commonly known as dwarf elder or danewort, and is widespread from Central Europe to the Middle East. Generally, SE leaves are widely used in herbal medicine for the treatment of kidney and lung diseases, inflammation-related gastrointestinal disorders, rheumatoid arthritis, fever, infections, sore throat, and bites [1-4].

Several studies revealed that SE leaves comprise various compounds such as flavonoids, polyphenols, triterpenes, tannins, iridoids, phytosterols, lectins, sugars, fibers, vitamins, and minerals [5-8]. The main therapeutic benefits of SE extracts are related to their antioxidant and anti-inflammatory properties, making them valuable sources for food, cosmetic and pharmaceutical 
industries, as well as medicine. However, the compounds from SE extract exhibit poor water solubility, which limits their bioavailability and therapeutic applications. Also, because of domestic processes (thermal and mechanical) and storage conditions, most of the bioactive substances of SE extract are susceptible to degradation, and thus, a significant portion of phytochemicals is not absorbed $[9,10]$.

A solution to overcome these drawbacks could be the encapsulation of SE extract in various carriers. For the encapsulation of bioactive compounds or extracts, several carriers have been reported: (i) natural or synthetic polymers [11,12]; (ii) micro/nanofibers [13,14]; (iii) lipids including micro/nanoemulsions, lipid vesicles and solid lipid nanoparticles [15-18]; (iv) cyclodextrins [19,20]; and (v) other types, e.g., niosomes, inorganic nanoparticles and nanocrystals [21,22].

The encapsulation into lipid vesicles causes better stability, less impact on natural compounds, decreased toxicity and side effects, and lower frequency of dose administration, and thus, enhanced patient compliance and therapeutic efficiency $[23,24]$. Successful attempts to enclose bioactive compounds into lipid vesicles, like liposomes, transfersomes, ethosomes, etc., are reported [25,26]. Liposomes are microscopic spheres with an aqueous core surrounded by one or more outer shells consisting of lipids in a bilayer [27], while transfersomes are elastic or flexible liposomes which consist of lipids and a single chain surfactant (e.g., sodium cholate, deoxycholate, Span 80, Tween 80) that acts as an "edge activator" and destabilizes the lipid bilayers, providing greater flexibility comparing to the liposomes [28]. Novel lipid vesicles called ethosomes are other possible carriers which consist of a lipid layer and a high ethanol concentration (20-40\%), providing greater flexibility than that of liposomes [29].

Only a few studies on the encapsulation of bioactive compounds from Sambucus species were reported. For instance, Stanciuc et al. [30] encapsulated bioactive compounds from Sambucus nigra L in whey proteins and a combination of whey proteins isolates and pectin proving higher heat stability. Sobieralska and Kurek [31] demonstrated the superior benefits of Sambucus nigra extract encapsulated in maltodextrin- $\beta$-glucan microcapsules in comparison with maltodextrin with Arabic gum ones in terms of efficiency and stability. Moreover, Bryła et al. [32] compared three types of lecithins (egg yolk, soybean and sunflower) for obtaining liposomes loaded with Sambucus nigra L extract, and none of lecithins produced structures with good stability and encapsulation efficiency simultaneously.

Herein, we report the design of lipid vesicles for encapsulation SE leaves extract for improved efficiency. To our knowledge, this is the first report regarding the encapsulation of SE leaves extract in three types of lipid vesicles, including liposomes, transfersomes, and ethosomes. Furthermore, the radical scavenger activity of SE leaves extract free and loaded on lipid vesicles on the L-929 mouse fibroblasts cell line was assessed, resulting in a cytoprotective effect of cells.

\section{Materials and Methods}

\subsection{Materials}

Phosphatidylcholine from egg yolk (PC), cholesterol, sodium cholate, Triton X-100, Folin-Ciocalteu reagent, 2,2-diphenyl-1-picrylhydrazyl (DPPH), and sodium carbonate were purchased from Sigma-Aldrich Co. (Merck Group, Darmstadt, Germany). For chromatographic analysis, the following standard HPLC-grade compounds were used: Gallic acid (Alfa Aesar, Ward Hill, MA, USA 98\%), protocatechuic acid (Tokyo Chemical Industry, Tokyo, TCI, Japan >98\%), catechin hydrate (Sigma, Merck Group, Darmstadt, Germany >98\%), vanilic acid (TCI, >98\%, GC-grade), caffeic acid (Sigma, 98\%), syringic acid (Molekula GmbH, Munich, Germany, >98.5\%), (-)epicatechin (TCI, >98\%), quercetin (Sigma, >95\%, HPLC-grade), rutin hydrate (Sigma, 95\%), chlorogenic acid (HWI Group, Alpen Aan de Rijn, The Netherlands, primary reference standard), trans- $p$-coumaric acid (Sigma-Aldrich, analytical standard), myricetin (Sigma, >96\%), rosmarinic acid (Sigma, >98\%), trans-resveratrol (Sigma-Aldrich, certified reference material), kaempferol (Sigma, >97\%). The solvents used for mobile phases and samples preparation were acetonitrile (Riedel-de Haen, Honeywell Riedel-de-Haën, Seelzer, Germany), ethanol (Riedel-de Haen), formic acid (Merck Group, Darmstadt, Germany), 
and ultrapure water (Millipore Direct-Q3UV water system, version Q3UV, catalog product no. C9185, Merck Group, Darmstadt, Germany) equipped with a Biopack UF cartridge. For oxidative stress induction assay we used Eagle's Minimum Essential Medium (EMEM), Phosphate-Buffered Saline (PBS), fetal equine serum (FES), 0.25\% Trypsin-Ethylene-Diamine-Tetraacetic Acid (EDTA) solution, penicillin-streptomycin-neomycin mixture in $0.9 \% \mathrm{NaCl}(10,000 \mu \mathrm{g} / \mathrm{mL} / 10,000 \mathrm{U} / \mathrm{mL})(\mathrm{PSN})$, L-ascorbic acid powder, $\gamma$-irradiated, hydrogen peroxide aqueous solution $30 \%(w / w)$ purchased from Sigma-Aldrich Co. (Germany). We used L-929, murine fibroblast cell line (ATCC ${ }^{\circledR}$ CRL-6364 ${ }^{\mathrm{TM}}$ ), cultured in EMEM, high-glucose medium supplemented with $10 \% \mathrm{FES}$ and $1 \%$ PSN, at $37^{\circ} \mathrm{C}$ in an atmosphere of $5 \% \mathrm{CO}_{2}$. The Cell Titer $96^{\circledR}$ A Queous Non-Radioactive Cell Proliferation Assay was supplied from Promega Corporation (Madison, WI, USA).

\subsection{Vegetal Material}

The SE leaves were harvested at their maturity from Dambovita County, Romania (latitude: $45^{\circ} 18^{\prime} 15.4^{\prime \prime} \mathrm{N}$, longitude: $25^{\circ} 23^{\prime} 28.4^{\prime \prime}$ E) and identified by the botanical team of INCDCF-ICCF Bucharest, Romania. SE leaves were selected as vegetal material for the extract preparation considering their bioactive phytochemicals, including polyphenolic compounds, which determined protection against reactive oxygen species [33].

\subsection{Preparation of SE Extract}

The SE leaves were washed with distilled water, dried at room temperature $\left(25^{\circ} \mathrm{C}\right)$, and milled into a fine powder. The grounded vegetal material $(50 \mathrm{~g})$ was put in $500 \mathrm{~mL} 50 \%(v / v)$ ethanol-water mixture, and then refluxed for $1 \mathrm{~h}$ under stirring. The resulting suspension was filtered off and evaporated at reduced pressure $\left(72-75 \mathrm{~mm} \mathrm{Hg}\right.$ ), at $60^{\circ} \mathrm{C}$, using a rotary evaporator (Laboranta 4000, Heidolph Instruments GmbH \& Co. KG, Schwabach, Germany) and then re-dissolved in 50\% ethanol aqueous solution. The obtained SE extract with $47.20 \mathrm{mg} / \mathrm{mL}$ concentration, whose extraction yield was $23.6 \%$, was stored in a refrigerator at $4{ }^{\circ} \mathrm{C}$.

\subsection{Determination of Total Polyphenols Content}

The total polyphenol content of SE extract was determined using the Folin-Ciocalteu method [34]. Briefly, $1 \mathrm{~mL}$ extract, $10 \mathrm{~mL}$ of water and $1 \mathrm{~mL}$ of Folin-Ciocalteu reagent (diluted 10 times) were mixed, and the volume was completed up to $25 \mathrm{~mL}$ with $5 \%(\mathrm{wt})$ aqueous solution of sodium carbonate. After $30 \mathrm{~min}$, the absorbance of the resulted solution was read at $760 \mathrm{~nm}$, using a UV/VIS spectrophotometer (Helios $\lambda$, ThermoFisher Scientific, Waltham, MA, USA). The total polyphenolic compounds content was determined based on a calibration curve for gallic acid $(0.01-0.1 \mathrm{mg} / \mathrm{mL}$ concentration range; $\left.y=0.01322 x+0.0272, R^{2}=0.99574\right)$. The results were presented as milligrams of gallic acid equivalents per gram of dry extract (mg GAE/g).

\subsection{High-Performance Liquid Chromatography Analysis of SE Extract}

The phenolic compounds separation, identification and quantification were performed using reverse-phase high-performance liquid chromatography (HPLC; Shimadzu Nexera 2, Shimadzu Corporation, Kyoto, Japan) with a photodiode array detector (SPD-M30A) operating in the 250-650 nm wavelength range and a LC-20ADXR quaternary pump (Shimadzu Corporation), DGU-20A $5 R$ vacuum degasser (Shimadzu Corporation), SIL-30 AC autosampler (Shimadzu Corporation) and CTO-20AC column oven (Shimadzu Corporation). The chromatograms were acquired and processed with LabSolutions Lite LC/GC software (version 5.82, Shimadzu Corporation). The separation was performed by gradient elution on a Nucleosi ${ }^{\circledR}$ reversed-phase $\mathrm{C}_{18}$ column (Macherey-Nagel GmbH \& Co. KG, Düren, Germany) $4.6 \times 100 \mathrm{~mm}(2.7 \mu \mathrm{m})$ using two mobile phases: $2.5 \%$ aqueous formic acid solution (mobile phase A) and $90 \%$ aqueous acetonitrile with $2.5 \%$ formic acid (mobile phase B). The elution program was established after modification of the method proposed by Nicoletti et al. [35]: $1.5 \mathrm{~min}$ isocratic elution with $5 \%$ mobile phase B, followed by 6 min linear gradient to $9 \%$ mobile 
phase B and another 6 min linear gradient to $13.5 \%$ B, isocratic elution with $13.5 \%$ B for 2.5 min, 5 min linear gradient to $18.5 \% \mathrm{~B}$, followed by 1 min linear gradient to $22.5 \% \mathrm{~B}$, isocratic elution with $22.5 \%$ mobile phase B for $3.5 \mathrm{~min}, 4.5$ min linear gradient to $35 \%$ mobile phase B, 5 min linear gradient to $100 \%$ mobile phase $B$ and isocratic elution for $5 \mathrm{~min}$ with $100 \%$ mobile phase $\mathrm{B}$. At the end, the gradient elution was returned to the initial concentration, and before the next injection the column was equilibrated for $10 \mathrm{~min}$. The flow rate was set at $0.4 \mathrm{~mL} / \mathrm{min}$, and the separation was performed at $20^{\circ} \mathrm{C}$, using an injection volume of $1 \mu \mathrm{L}$. All solvents used for the mobile phase were previously filtered off through $0.45 \mu \mathrm{m}$ nylon membranes and degassed. The chromatogram of SE extract was recorded at $326 \mathrm{~nm}$ wavelength.

Phenolic compounds were identified by comparing their retention times and UV-vis spectra similarity with the standard substances. Each HPLC-grade standard substance was dissolved in ethanol at $100 \mathrm{mg} / \mathrm{L}$ concentration, and the calibration curves for the phenolic compounds quantification were obtained by injecting five solutions with concentrations ranging from $0.5-100 \mathrm{mg} / \mathrm{L}$ for each standard. For the quantification of each standard phenolic compound, a chromatogram was recorded at the maximum absorption wavelength, and the retention time and coefficient of the calibration curve were presented in Supplementary Information.

\subsection{Preparation of SE Extract-Loaded Lipid Vesicles}

Three types of lipid vesicles, liposomes, transfersomes and ethosomes were employed to entrap the SE extract. All lipid vesicles were prepared using PC as lipid due to its amphiphilic nature (polar head group and lipophilic tail), and its capacity to organize itself spontaneously into bilayers. Apart from PC, cholesterol was included in liposomes formulation due to its influence on the phospholipid alkyl chain free movement, which led to a reduced bilayer permeability and in vivo and in vitro enhanced stability of the liposomes. Sodium cholate was used in transfersomes formulation as "edge activator" due to its ability to destabilize the lipid bilayers, providing more flexibility to the transfersomes.

The SE-loaded liposomes and transfersomes were prepared using thin-film hydration method, followed by ultrasound treatment and extrusion. Briefly, the SE extract, phosphatidylcholine and cholesterol (for liposomes) or sodium cholate (for transfersomes) were dissolved in $5 \mathrm{~mL}$ chloroform/methanol mixture $(1 / 3, v / v)$ and methanol, respectively. Then, the solutions were kept at room temperature overnight to facilitate the phosphatidylcholine swelling. The lipid solutions were poured into a round-bottom flask and evaporated in a rotary evaporator at $35^{\circ} \mathrm{C}$ for $2 \mathrm{~h}$. After solvent removal, the resulting thin lipid film was hydrated with distilled water at $35^{\circ} \mathrm{C}$. The dispersions were kept for $2 \mathrm{~h}$ at room temperature for stabilization.

The formulations based on ethosomes were prepared using the cold method. Firstly, phosphatidylcholine was dissolved in ethanol and kept for $24 \mathrm{~h}$ at room temperature for swelling. Then, SE extract was added to phosphatidylcholine solution. The resulted mixture was kept under vigorous stirring in a covered round-bottom flask to avoid ethanol evaporation, and then heated distilled water at $30^{\circ} \mathrm{C}$ was added slowly under stirring. The dispersions were kept at room temperature for $30 \mathrm{~min}$ under continuous magnetic stirring.

All obtained formulations were ultrasounds treated in an ultrasonic bath (Sonorex Digital 10P, Bandelin Electronic GmbH \& Co., Berlin, Germany) filled with ice, for $20 \mathrm{~min}$, at a controlled power of $20 \%$ of amplitude. The lipid-containing extract vesicles were extruded first using $0.4 \mu \mathrm{m}$ and then $0.2 \mu \mathrm{m}$ pore size filters with 5 cycles for each pore size. Empty liposomes, transfersomes and ethosomes were prepared as the controls. All samples were obtained in triplicate and stored in a refrigerator at $8{ }^{\circ} \mathrm{C}$ for no more than $48 \mathrm{~h}$ prior to further use. More details about lipid formulations containing SE extract are provided in Table 1. 
Table 1. The characteristics of Sambucus ebulus (SE) extract-loaded lipid vesicles.

\begin{tabular}{cccccc}
\hline Sample & Formulation & EE (\%) & Size (nm) & PDI & $\xi(\mathbf{m V})$ \\
\hline SE@L & PC:Cholesterol:SE $=10: 1: 2(w / w)$ & $80.05 \pm 0.51$ & $123 \pm 2.50$ & $0.182 \pm 0.01$ & $-43 \pm 1.03$ \\
SE@T & PC:Sodium cholate:SE $=8: 2: 2(w / w)$ & $75.10 \pm 1.12$ & $155 \pm 3.31$ & $0.161 \pm 0.02$ & $-39 \pm 0.50$ \\
SE@E & PC:SE = 8:2.5 $(w / w) ; \mathrm{EtOH}: \mathrm{H}_{2} \mathrm{O}=7: 3(v / v)$ & $85.10 \pm 1.50$ & $190 \pm 2.53$ & $0.209 \pm 0.01$ & $-37 \pm 0.23$ \\
L & PC:Cholesterol $=10: 1(w / w)$ & - & $49 \pm 1.52$ & $0.440 \pm 0.01$ & - \\
T & PC:Sodium cholate $=8: 2(w / w)$ & - & $105 \pm 0.23$ & $0.379 \pm 0.02$ & - \\
\hline
\end{tabular}

\subsection{Characterization of SE-Loaded Lipid Vesicles}

For the SE extract-loaded lipid vesicles the size, polydispersity index (PDI) and entrapment efficiency (EE), as well as zeta potential values, were determined. The first step for determination of entrapment efficiency was the separation of SE-loaded lipid vesicles from the free extract by centrifugation $\left(10,000 \mathrm{rpm}\right.$ at $\left.5{ }^{\circ} \mathrm{C} / 30 \mathrm{~min}\right)$, and then they were redispersed in water. The centrifugation was repeated twice, and then the sediment was mixed with $0.5 \mathrm{~mL}$ Triton $\mathrm{X}-100(0.5 \%)$ and subsequently vortexed for breaking down the lipid membranes. The final suspension was diluted ten times with methanol. EE was calculated using the following Equation (1):

$$
E E(\%)=\frac{Q_{1}}{Q_{t}} \times 100
$$

here $Q_{1}$ is the amount of polyphenols entrapped in lipid vesicles and $Q_{t}$ is the total amount of polyphenols from the extract. The total of the polyphenol amounts entrapped in lipid vesicles was assessed by Folin-Ciocalteu assay, and empty lipid vesicles were used as control.

The particle size and PDI of lipid vesicles were determined by dynamic light scattering (DLS) using a particle size analyzer (Beckman Coulter N4 PCS Submicron, Coulter Company, measurement range of $3 \mathrm{~nm}-3 \mu \mathrm{m})$. The lipid vesicle dispersions were diluted ten times with water, and the measurements were performed at $25^{\circ} \mathrm{C}$ in triplicate with ten runs for each determination. The zeta potential values, $\xi$, of SE-loaded lipid vesicles were determined using a Zetasizer (Malvern Panalytical Ltd., Malvern, UK). The $\xi$ values were measured on undiluted samples at $25^{\circ} \mathrm{C}$ in triplicate.

The lipid vesicles containing SE extract were investigated using various microscopy techniques. Atomic force microscopy (AFM) was performed with an XE-100 microscope (Park Systems Corp., Suwon, Korea) in true non-contact ${ }^{\mathrm{TM}}$ mode, as recommended for soft sample scanning. The scanner of the XE100 apparatus was equipped with flexure-guided, cross-talk eliminated scanners. All AFM images were recorded with sharp tips ( $<8 \mathrm{~nm}$ tip apex), NCHR type from Nanosensors ${ }^{\mathrm{TM}}$ (Neuchâtel, Switzerland), of $125 \mathrm{~mm}$ length, $30 \mathrm{~mm}$ width, spring constant $42 \mathrm{~N} / \mathrm{m}$, and $330 \mathrm{kHz}$ resonance frequency. For the AFM experiments, a small quantity of the sample was dispersed in ultra-pure water (Millipore Direct-Q3UV water system with Biopack UF cartridge), deposited on a clean silicon wafer and dried at room temperature. The recorded AFM images were processed with the XEI program (version 1.8.0, Park Systems) for displaying purposes. Representative line scans are presented (below each image) showing in detail the $\mathrm{z}$-scale of the images and the dimensions of the selected features (particles), as indicated along the selected line between two red arrows.

Dark-field microscopy was performed using a CytoViva system (CytoViva Inc., Auburn, AL, USA). Dark-field microscopy combined with hyperspectral imagery is a novel optical technique that allows for the localization of different types of unmarked particles with dimensions less than the diffraction limit. This is possible because on the hyperspectral camera is collected only the reflected or elastically-scattered light as a unique optical fingerprint of each material. It is based on the oblique illumination of the sample, such that the direct light is not collected, allowing it to distinguish objects with similar refractive indexes as glass coverslips.

Also, SE extract-loaded lipid vesicles were analysed using scanning electron microscopy (SEM) with a Tescan Vega 3 LMH microscope (Brno, Czech). The samples were prepared from a drop of 
lipid suspension that was further dried in a vacuum. Selected freeze-dried lipid vesicles were also investigated by SEM.

\subsection{In Vitro Release Polyphenols from SE Loaded Lipid Vesicles}

The polyphenols release profiles from lipid vesicle formulations were carried out using a dialysis membrane under sink conditions. The dialysis bag (14,000 molecular weight cut-off from Sigma-Aldrich, USA) in which was put a lipid vesicles suspension $(1.0 \mathrm{~mL})$ was immersed into $50 \mathrm{~mL} 0.1 \mathrm{M}$ phosphate buffer solution of $\mathrm{pH} 7.4$ at $37^{\circ} \mathrm{C}$ under magnetic stirring $(100 \mathrm{rpm} / \mathrm{min})$. Aliquots of $1.0 \mathrm{~mL}$ were withdrawn at predetermined intervals, and the release medium was refilled with the same volume.

The polyphenols from the released medium were determined by UV-vis spectrophotometry using Folin-Ciocalteu assay and compared with the free extract dissolution in the same medium, at a PBS pH of 7.4. The polyphenols release profiles were performed in triplicate.

\subsection{Determination of Radical Scavenging Activity}

The radical scavenging activity of the extract was evaluated using the Sanchez-Moreno et al. assay [36]. Briefly, each sample $(50 \mu \mathrm{L})$ at different concentrations (serial dilution of SE extract ranging from $0.001-10 \mathrm{mg} / \mathrm{mL}$ ) was mixed with $2950 \mu \mathrm{L}$ of DPPH methanolic solution $(0.025 \mathrm{~g} / \mathrm{L})$. All mixtures were shaken vigorously and kept in dark conditions at room temperature for $30 \mathrm{~min}$. The solution absorbance was measured at $517 \mathrm{~nm}$ wavelength. The radical scavenger activity was evaluated based on the percentage of DPPH radical inhibition and computed using Equation (2):

$$
\% \text { RSA }=\frac{A_{0}-A_{\text {sample }}}{A_{0}} \times 100
$$

where $A_{0}$ is the control absorbance and $A_{\text {sample }}$ is the sample absorbance.

Quercetin $(0.0001-1 \mathrm{mg} / \mathrm{mL})$ and caffeic acid $(0.0001-1 \mathrm{mg} / \mathrm{mL})$ were used as positive controls. Experiments for radical scavenger capacity assessment were carried out in five replicates.

\subsection{Induced Oxidative Stress Assay}

The L-929 fibroblast cells were seeded on glass coverslips or plastic wells 2 days before experiments to achieve a confluence of $\sim 85 \%$ and transferred to 96 -well assay plates at a density of $10^{5} \mathrm{cells} / \mathrm{mL}$. Then, the oxidative stress was induced by exposure to various concentrations of hydrogen peroxide aqueous solution $(1,10,20,50$ and $100 \mathrm{mM})$ for $4 \mathrm{~h}$ for determination of the $\mathrm{IC}_{50}$ cell viability. For assessing the cytoprotective effect of SE extract free from and entrapped into lipid vesicles, L-929 cells were treated for 1, 12 and $24 \mathrm{~h}$ with empty lipid vesicles, free SE extract and SE-loaded lipid vesicles, and then the cell viability was determined using MTS assay. The medium was changed, and the cells were exposed to the $\mathrm{IC}_{50}$ concentration of hydrogen peroxide solution $(50 \mathrm{mM})$ for another $24 \mathrm{~h}$. As a reference substance, ascorbic acid was used in the same concentrations as tested lipid formulations $(5,10$ and $25 \mu \mathrm{g} / \mathrm{mL}$ ). The absorbance was read using a Microplate Reader (Chameleon V Plate Reader, LKB Instruments, Victoria, Australia) at a wavelength of $490 \mathrm{~nm}$. The control was considered as the culture medium with and without hydrogen peroxide. All samples were sterilized by UV exposure for two hours. Experiments were carried out in triplicate.

\subsection{Statistical Analysis}

Statistical analysis of the data was performed using SPSS 18.0 (SPSS Inc., Chicago, IL, USA). The results were presented as mean value \pm SD. Differences were considered significant where $p<0.05$. The $\mathrm{IC}_{50}$ values for RSA and cell viability were computed using GraphPad Prism version 7 software (GraphPad Software Inc., San Diego, CA, USA). 


\section{Results}

\subsection{Characterization of SE Extract}

SE leaves were selected as vegetal material from a database containing plants with radical scavenging activity considering its significant amount of phenolic compounds and superior valorisation of vegetal material. The SE leaves extract was characterized for total polyphenols content, chemical profiling, radical scavenging capacity, and cytoprotective effect on hydrogen peroxide-induced toxicity on the L-929 fibroblast cell line.

The hydroalcoholic extract from SE leaves exhibited a significant polyphenols content, $25.50 \pm 0.010 \mathrm{mg} \mathrm{GAE} / \mathrm{g}$ dry material, in accordance with the literature data. For instance, Feizbakhsh et al. (2010) reported a value for phenolic content of $27.40 \pm 0.8 \mathrm{mg}$ GAE/g dry material for an ethanolic extract of SE leaves [37].

The SE extract chemical profiling was investigated using reverse-phase HPLC analysis, in which was used a mixture of eleven phenolic compounds, from which four were detected and quantified (Figure 1). The most abundant compound was chlorogenic acid (14.389 $\pm 0.018 \mathrm{mg} / \mathrm{g}$ extract). Also, caffeic acid was presented in a significant amount $(2.997 \pm 0.004 \mathrm{mg} / \mathrm{g}$ extract). On the other hand, rutin $(0.564 \pm 0.001 \mathrm{mg} / \mathrm{g}$ extract $)$ and quercetin $(0.073 \pm 0.001 \mathrm{mg} / \mathrm{g}$ extract $)$ were also identified and quantified, but they were in low concentrations in the SE extract. The presence of identified compounds was consistent with previous studies [37].

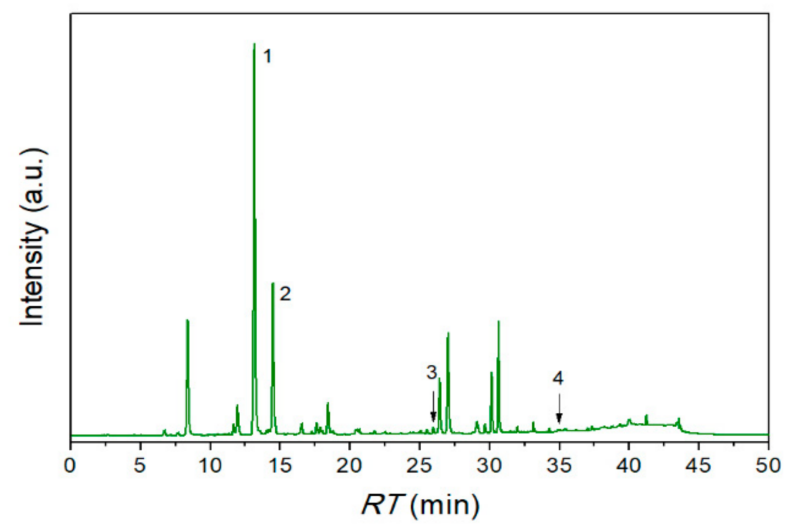

Figure 1. Chromatogram of SE extract at $326 \mathrm{~nm}: 1-C h l o r o g e n i c ~ a c i d: ~ R T=13.160 \pm 0.002 \mathrm{~min}$; $c=14.389 \pm 0.018 \mathrm{mg} / \mathrm{g}$ extract; 2-Caffeic acid: $R T=14.500 \pm 0.004 \mathrm{~min} ; c=2.997 \pm 0.004 \mathrm{mg} / \mathrm{g}$ extract; 3-Rutin: $R T=25.970 \pm 0.002 ; c=0.564 \pm 0.001 \mathrm{mg} / \mathrm{g}$ extract; 4-Quercetin: $R T=34.952 \pm 0.002$, $c=0.073 \pm 0.001 \mathrm{mg} / \mathrm{g}$ extract.

The radical scavenging capacity of SE extract was assessed using the DPPH method that reflects the capacity of a compound to induce the inhibition of $50 \%$ of the DPPH radical $\left(\mathrm{IC}_{50}\right)$. In comparison with the $\mathrm{IC}_{50}$ of SE $(10.33 \pm 0.056 \mu \mathrm{g} / \mathrm{mL})$, it was approximately 1.7 and 2.4 times lower than that of quercetin $(5.97 \pm 0.026 \mu \mathrm{g} / \mathrm{mL})$ and caffeic acid $(4.370 \pm 0.022 \mu \mathrm{g} / \mathrm{mL})$, respectively.

\subsection{Characterization of SE Extract-Loaded Lipid Vesicles}

The features of lipid vesicles influence their in vitro and in vivo behaviour; hence, their characterization is an essential step in their application in biomedical and cosmetic field. The size, PDI, EE and stability over three months of SE extract-loaded lipid vesicles were determined using empty lipid vesicles as control. The composition of lipid vesicles and their features were gathered in Table 1.

The formulations were selected after one-factor-at-a-time experiment (see Supplementary Information). Four factors (PC/SE extract ratio, evaporation temperature, stirring rate, PC/cholesterol 
(sodium cholate) ratio) were assessed for liposomes and transfersomes, respectively. Two factors (PC/SE extract ratio and water/ethanol ratio) were assessed for ethosomes.

The size enlargement after the extract loading process was caused by the incorporation of phytochemicals in the vesicle structure. The SE extract contains phytocompounds with different polarity. Therefore, according to the literature [38] their localization within lipid vesicles is different, for instance, non-polar compounds are located in the bilayer, and the polar ones in the aqueous inner core, resulting an increase of particle size. Also, the incorporation of non-polar compounds probably induces a fluidization effect on lipid vesicles membrane by producing a PC perturbation leading to a deep insertion of polyphenols in phospholipid bilayer, as reported for eugenol and isoeugenol [39]. The results are in agreement with literature data, an increase of particle size being reported because of incorporation of grape-seed [40,41], liquorice [38] and Polygonum aviculare [42] extracts. The size of SE-loaded lipid vesicles increases in order: liposomes $<$ transfersomes $<$ ethosomes. Liposomes and tranfersomes had lower size due to the presence of cholesterol, and sodium cholate in the lipid bilayer that compete with the extract. So, the bilayer could accommodate only a low amount of polyphenols, leading to a decreased size.

The PDI values show the homogeneity of systems. Generally, PDI values less than 0.1 indicate a homogeneous population, while values higher than 0.3 show a big heterogeneity [43]. All loaded lipid vesicles showed narrow size distribution (PDI $<0.21$ ), proving a good homogeneity and a low tendency of aggregation. The incorporation of SE extract improved the homogeneity, while the empty vesicles had a wider size distribution than SE-loaded vesicles in agreement with literature data $[44,45]$. The zeta potential values were in the range of $-43 \pm 1.03 \mathrm{mV} \div-37 \pm 0.23 \mathrm{mV}$ being in accordance with the literature data, all samples indicated moderate stability [46].

The AFM investigation of SE-loaded samples revealed randomly distributed quasi-spherical particles for all type of lipid vesicles, with size of tens of $\mathrm{nm}$ (selected vesicles having the average diameter of $39 \mathrm{~nm}$ in the case of liposomes (Figure 2A), $62 \mathrm{~nm}$ for transfersomes (Figure 2B) and $86 \mathrm{~nm}$ for ethosomes (Figure 2C)). Larger and more homogeneously distributed lipid vesicles are noticed for SE@E sample (Figure 2C), while smaller and more compacted for SE@L sample (Figure 2A). The vesicular nature of samples is confirmed by their spiky (noisy-like) profile (see for examples the lines below Figure 2B,C).

The AFM images of SE extract-loaded lipid vesicles showed particles with lower dimensions than in the case of SEM analysis (see Supplementary Information, Figures S4 and S5), probably because of the aggregation of nanoparticles during the freeze-drying process. However, the aggregates of liposomes preserve the shape of primary nanoparticles, having uniform size, in the range of $1-3 \mu \mathrm{m}$. The size of lipid vesicles obtained by AFM analysis are smaller than the hydrodynamic diameters measured by DLS or the size determined by SEM (Supplementary Information, Figure S6), but the same order of increase for lipid vesicle dimensions was noticed (Table 1).

Hyperspectral images of SE@E sample were obtained using enhanced dark field microscopy mounted on an Olympus BX51 upright microscope (Olympus, Tokyo, Japan) equipped with a CytoViva ${ }^{\circledR}$ enhanced dark-field condenser (CytoViva Inc., Auburn, AL, USA) and patented illumination with liquid-core optical fiber. Using a $60 \times$ microscope objective oil immersed, the sample was scanned (the exposure time for a frame is established in accordance with the producer procedure and it is of the order of few seconds). The acquired images are corrected with the lamp spectrum (Figure 3B) and spectra are collected in the isolated points and cumulated on the same plot (Figure 3C). It is observed that points where nanoparticles are located are isolated from each other, and the light scattering spectra show similar maximum intensities, indicating a narrow size distribution of lipid vesicles. 

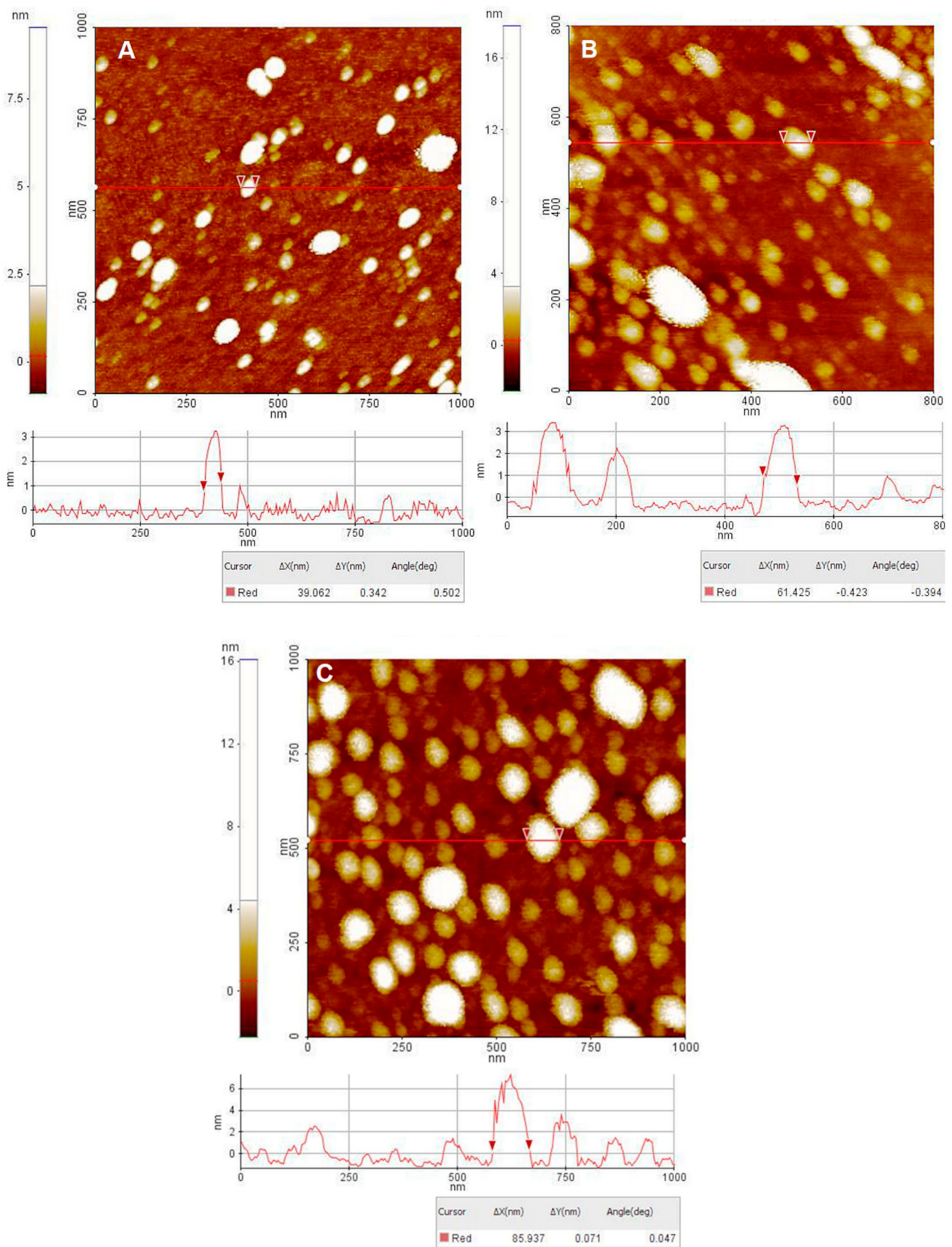

Figure 2. 2D AFM images together with representative line scans (surface profile) of the imaged samples: (A) liposomes, (B) transferosomes and (C) ethosomes. 

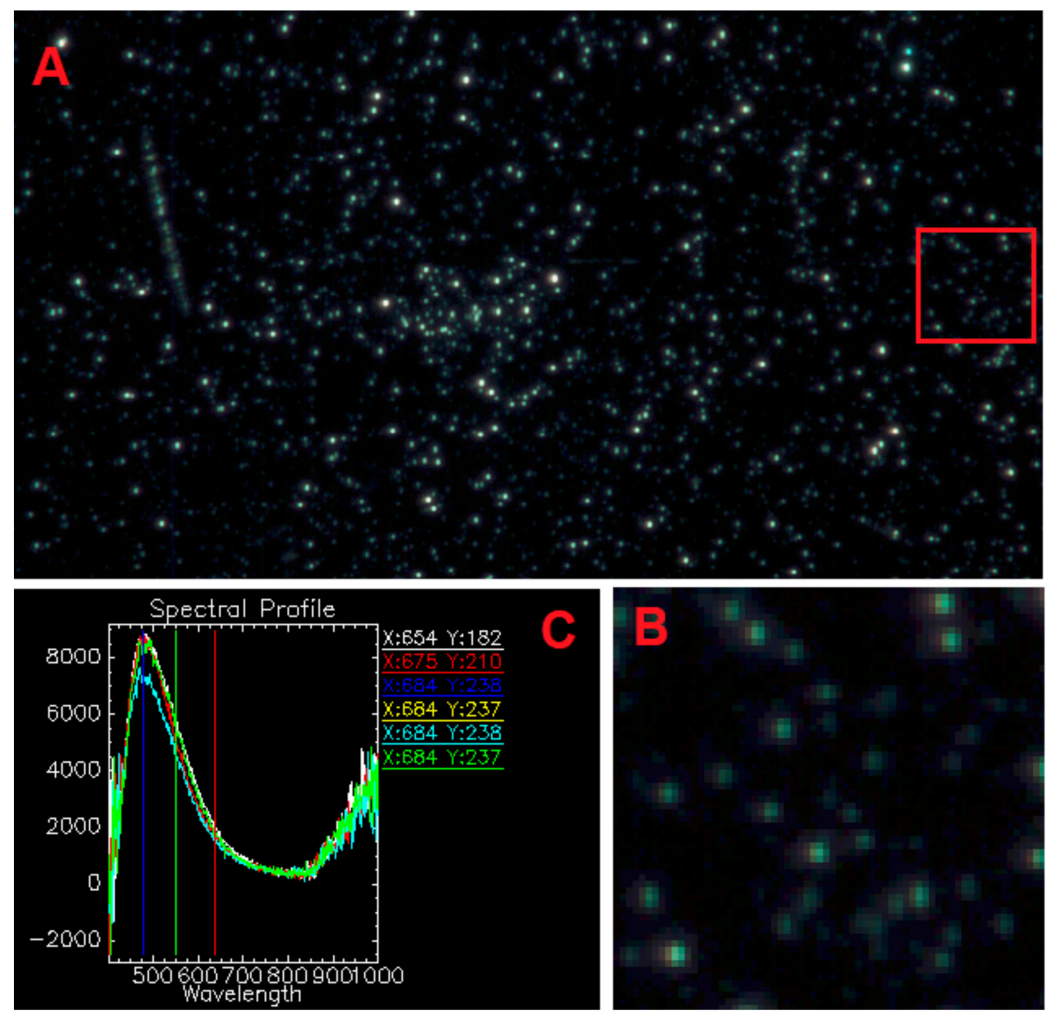

Figure 3. Image recorded by enhanced dark-field microscopy using Cytoviva (A); magnification of marked area from figure A corrected with the lamp spectrum (B) and spectra collected in the isolated points (C).

The entrapment efficiency of SE extract in all lipid vesicles was above $75 \%$ and increased in order liposomes $<$ transfersomes < ethosomes, the applied preparation methods being efficient. Similar results were reported for the entrapment efficiency of Polygonum aviculare [42], Glycyrrhiza glabra L. [38] and Artemisia arborescens [47]. For liposomes it was obtained the lowest EE because of the cholesterol presence that lowered the incorporation efficiency of polyphenols. The influence of cholesterol can be explained by two phenomena: (i) lipophilic polyphenols compete with cholesterol molecules for the lipophilic space in the lipid bilayer [48] and/or (ii) cholesterol decreases the flexibility of the lipid bilayer and thus, the possibility of integration of lipophilic molecules into the lipid membrane [49].

On the other hand, sodium cholate used as "edge activator" in transfersomes may improve the flexibility of lipid bilayer, leading to the accommodation of a higher amount of polyphenols than in liposomes. Moreover, transfersomes had a smaller quantity of extract than ethosomes, their EE being slightly hindered by the competition between SE extract and the "edge activator" for the bilayer space in agreement with Gupta et al. results [50].

For the stability of loaded lipid vesicles evaluation, the samples were kept in a $10 \mathrm{~mL}$ amber-coloured glass vial and stored at $4{ }^{\circ} \mathrm{C}$ for 3 months. Since all formulations were protected by light, the oxidation and hydrolysis of the lipids caused by light were avoided. To assess the stability of samples, EE parameter was evaluated after different storage periods of time (0, 1, 2, 3 months). The SE-loaded lipid vesicles were stable for at least three months, with approximately the same amount of phytocompounds entrapped after one month (extract compounds loss $<0.65 \%$ ) and after 3 months (extract compounds loss $<3.35 \%$ ). No sedimentation of SE-loaded lipid vesicles was observed during storage, probably because the brownian motion and the diffusion rate, which in the case of nano-sized formulations are higher than the gravitational-induced sedimentation rate. 


\subsection{In Vitro Polyphenols Release Study}

The in vitro release of polyphenols from lipid vesicles was determined in PBS pH 7.4 at $37^{\circ} \mathrm{C}$, and the experimental data were presented in Figure 4. The amount of polyphenols delivered from SE extract was assessed using a Folin-Ciocalteu assay. One can notice that the release of polyphenols from the free extract exhibited a "burst effect", while in the case of SE extract entrapped into lipid vesicles, lower kinetics were determined. After $10 \mathrm{~h}$, almost all polyphenols from the free extract were released $(98.51 \pm 1.07 \%)$, while for all lipid formulations, the release rate was lower (bellow $70 \%$ ). The liposome-based formulations showed the slowest polyphenols release rate due to the presence of cholesterol, which increased the rigidity and decreased the permeability of the lipid bilayer. Transfersomes and ethosomes, because of their ultra-deformable nature, determined faster polyphenols release kinetics. To evaluate the mechanism of polyphenols release, three kinetics models were applied: Weibull (Equation (3)), Korsmeyer-Peppas (Equation (4)) and Higuchi (Equation (5)):

$$
\begin{aligned}
& \frac{M(t)}{M(\infty)}=1-e^{-a t^{b}} \\
& \frac{M(t)}{M(\infty)}=k_{K P} \times t^{n} \\
& \frac{M(t)}{M(\infty)}=k_{H} \times t^{1 / 2}
\end{aligned}
$$

where $M(t)$ represents polyphenols released at time $t$ and $M(\infty)$ represents the total amount of polyphenol located in the carrier; $k_{K P}, k_{H}$ are Korsmeyer-Peppas and Higuchi constants, and $a, b$ are Weibull function parameters.

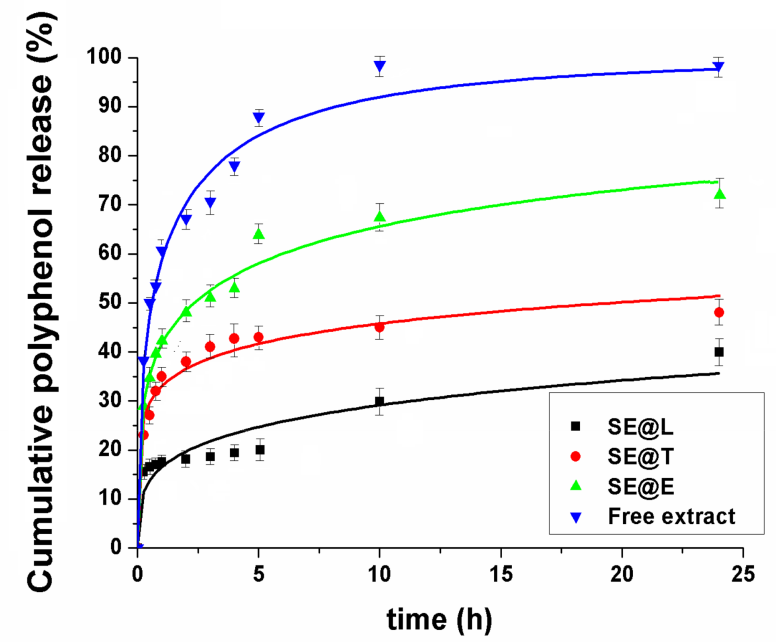

Figure 4. Polyphenols release profiles from SE extract-loaded lipid vesicles in comparison with free SE extract solubilization in PBS of $\mathrm{pH} 7.4$ fitted with the Weibull model.

In Table 2 are listed the correlation coefficients and parameters of mathematical models used for fitting the experimental data of polyphenol release from lipid vesicles in comparison with phytochemicals solubilization in PBS from SE hydro-alcoholic extract. The highest correlation coefficients were obtained for the Weibull Equation, for which $a$ parameter is a measure of the bio-compounds delivery rate and parameter $b$ indicates their transport [51]. Values of $b$ parameter lower than 0.75 suggest a Fickian diffusion of biomolecules, while for higher values of $b$ indicate a non-Fickian transport [52]. From all lipid-type formulations, $b<0.75$ suggests a Fickian diffusion. Korsmeyer-Peppas and Higuchi models were applied only for the first $60 \%$ cumulative release of polyphenols with correlation coefficients higher than 0.96 and 0.92 , respectively (Figure 5). In the 
Korsmeyer-Peppas's model, the $k_{K P}$ is a constant that depends on the carrier characteristics, and the coefficient $n$ shows the nature of the release mechanism. When $n \leq 0.45$, the release is dominated by the Fickian diffusion mechanism; the $0.45<n<0.89$ release follows anomalous diffusion (non-Fickian diffusion), and $n>0.89$ follows a super-case-II transport mechanism [53]. The $n$ and $k_{K P}$ values are listed in Table 2. For all samples, the coefficient $n$ is lower than 0.45 , indicating a Fickian diffusion mechanism in agreement with the Weibull model. In the Higuchi's model, $k_{H}$ is a constant proportional with the release rate in the burst stage of the delivery process. The SE-loaded liposomes presented a lower value for $k_{\mathrm{H}}$ (Table 2) than the other lipid formulations, indicating a less intense burst effect, probably due to their cholesterol content, which increased the rigidity of the lipid bilayer and altered its permeability. Also, Gibis et al. reported a lower burst effect of polyphenols from grape seed extract-loaded liposomes than their solubilization process, with the polyphenols transport having a diffusion-controlled mechanism [54,55].

Table 2. Correlation coefficients and parameters of the fitted experimental data.

\begin{tabular}{ccccccccc}
\hline \multirow{2}{*}{ Sample } & \multicolumn{3}{c}{ Weibull } & \multicolumn{3}{c}{ Korsmayer-Peppas } & \multicolumn{2}{c}{ Higuchi } \\
\cline { 2 - 9 } & $\boldsymbol{a}$ & $\boldsymbol{b}$ & $\boldsymbol{R}^{\mathbf{2}}$ & $\boldsymbol{n}$ & $\boldsymbol{k}_{\boldsymbol{K} \boldsymbol{P}}$ & $\boldsymbol{R}^{\mathbf{2}}$ & $\boldsymbol{k}_{\boldsymbol{H}}$ & $\boldsymbol{R}^{\mathbf{2}}$ \\
\hline Free extract & 0.885 & 0.455 & 0.918 & - & - & - & - & - \\
SE@L & 0.181 & 0.280 & 0.983 & 0.076 & 17.390 & 0.991 & 2.363 & 0.973 \\
SE@T & 0.400 & 0.184 & 0.984 & 0.221 & 32.568 & 0.963 & 12.507 & 0.922 \\
SE@E & 0.538 & 0.297 & 0.970 & 0.216 & 40.640 & 0.978 & 16.980 & 0.949 \\
\hline
\end{tabular}
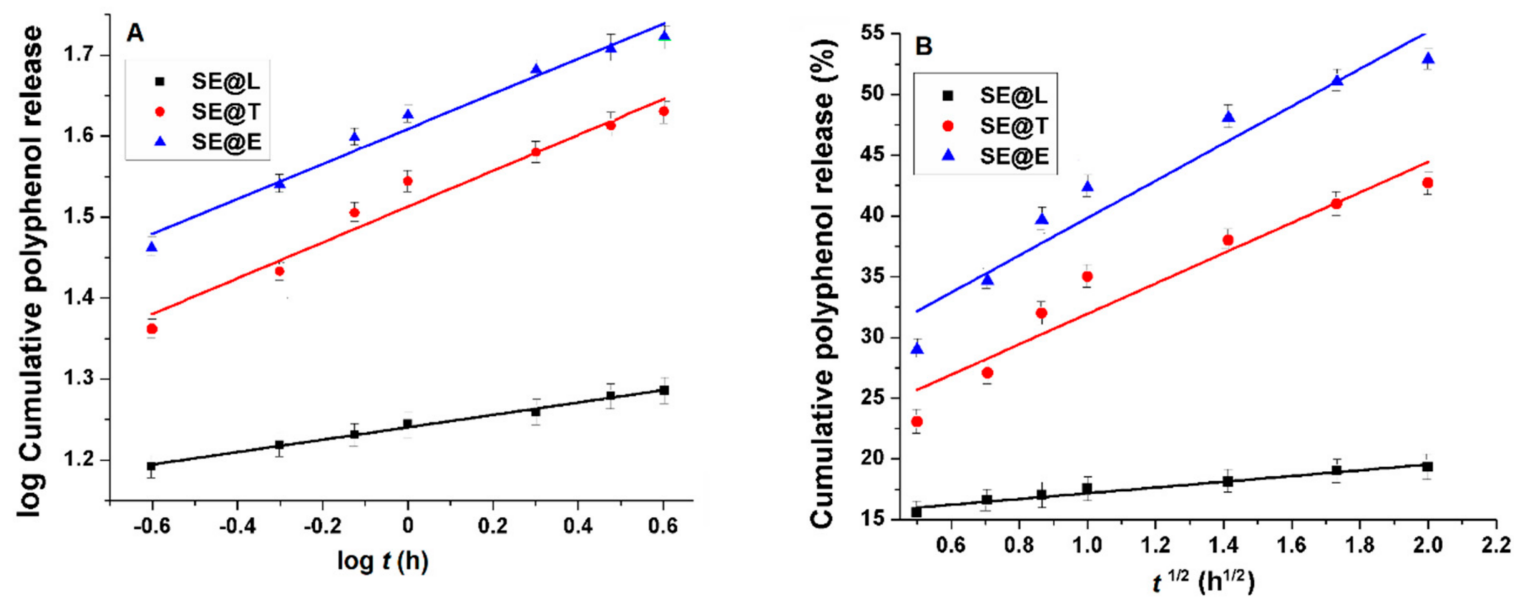

Figure 5. Polyphenols release profiles from SE extract-loaded lipid vesicles fitted with the Korsmayer-Peppas (A) and Higuchi (B) models.

\subsection{Effect of Pre-Treatment with SE Extract Free and Loaded into Lipid Vesicles against $\mathrm{H}_{2} \mathrm{O}_{2}-$ Induced Toxicity on L-929 Fibroblast Cell Line}

The viability of L-929 mouse fibroblast cells was evaluated after $4 \mathrm{~h}$ exposure at different concentrations of hydrogen peroxide aqueous solution in the range of $1-100 \mathrm{mM}$, its cytotoxicity being dose-dependent. The $\mathrm{IC}_{50}$ concentration of $\mathrm{H}_{2} \mathrm{O}_{2}$ was $50 \mathrm{mM}$. Hydrogen peroxide is not very reactive, but sometimes it can be toxic because it produces hydroxyl radicals [56]. Adding hydrogen peroxide solution to L-929 cells caused a significant increase in reactive oxygen species (ROS) level, which probably caused the death of L-929 cells. Three concentrations $(5,10,25 \mu \mathrm{g} / \mathrm{mL})$ for SE extract and SE-loaded lipid vesicles were selected, which are non-toxic and could prevent $\mathrm{H}_{2} \mathrm{O}_{2}$-induced cytotoxicity. Hence, L-929 fibroblast cells were pre-treated with free SE extract and SE-loaded lipid vesicles before adding hydrogen peroxide solution with $\mathrm{IC}_{50}$ concentration. One can notice enhanced viability when cells were previously treated with free and loaded SE extract (Figure 6), which suggested a cytoprotective effect against ROS of all free and loaded SE extract into lipid vesicles. 

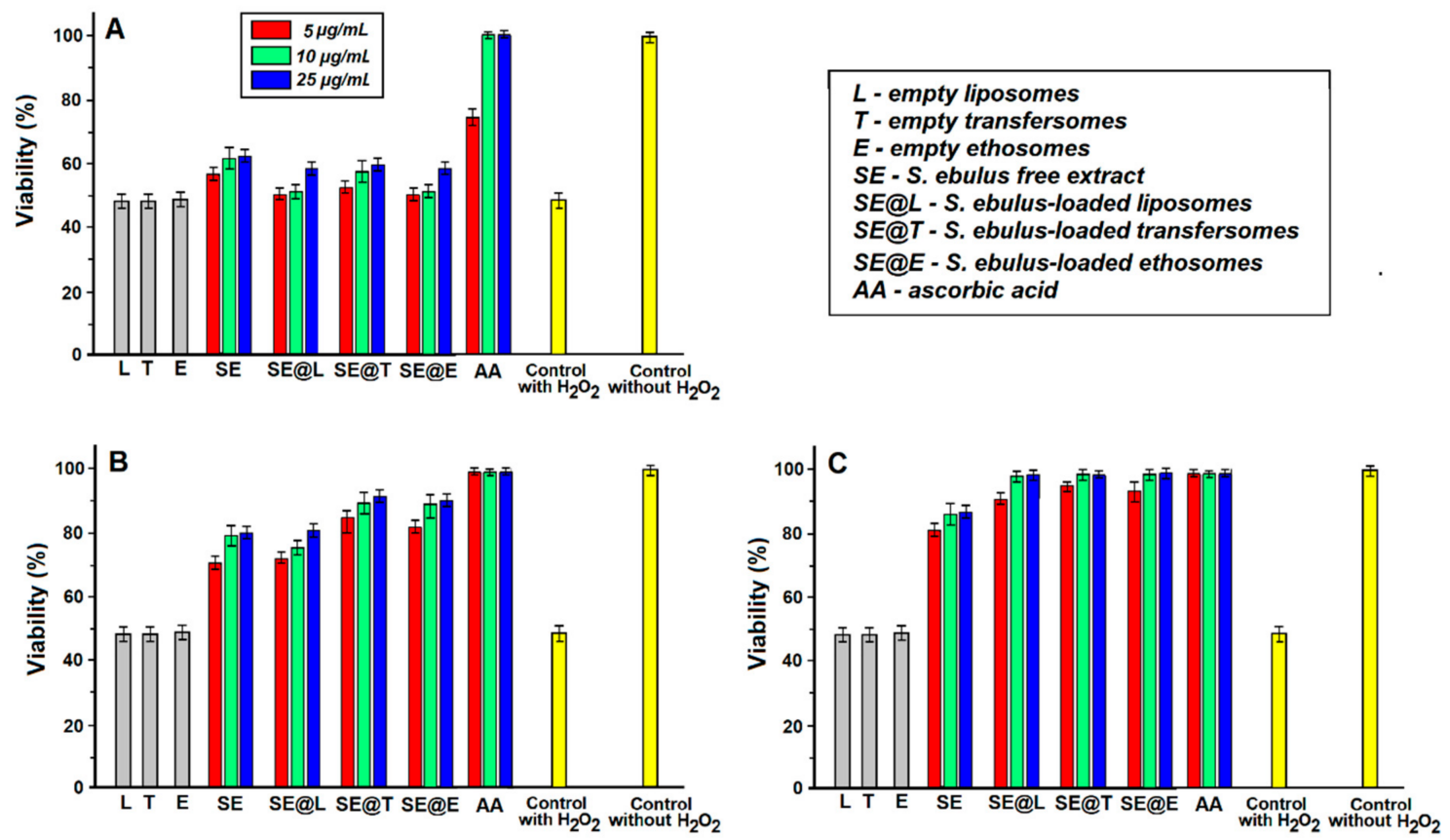

Figure 6. Effect of $\mathrm{H}_{2} \mathrm{O}_{2}$ on L-929 cell viability after exposure. Viability of L-929 mouse fibroblast cells after $1 \mathrm{~h}(\mathbf{A}), 12 \mathrm{~h}(\mathbf{B})$ and $24 \mathrm{~h}(\mathbf{C})$ pre-treatment with free and loaded-SE leaves extract before exposure at hydrogen peroxide solution of $50 \mathrm{mM}$ concentration during $4 \mathrm{~h}$ are shown.

Fibroblast cells developed some protective effects against the oxidative stress that was illustrated by a high cells' viability when a long pre-treatment $(24 \mathrm{~h})$ with SE extract free and loaded into lipid vesicles was applied. However, the effect was not significant in the case of short-term exposure of cells at SE extract free and loaded (1 h pre-treatment), suggesting that the development of the cytoprotective effect requires a long intracellular presence of the SE extract. All samples were able to protect L-929 cells against $\mathrm{H}_{2} \mathrm{O}_{2}$-induced cytotoxicity, probably due to their polyphenol content. Many studies confirmed that polyphenols may prevent the degenerative effects caused by oxidative stress, which could determine various deleterious events [57]. Polyphenols could act as antioxidants [58], and the mechanism has already been studied in vivo [59]. The main effect of phenolic compounds as antioxidants was determined by the presence of characteristic moieties, mainly phenylhydroxyl groups that can act as hydrogen donors, and hence can react with ROS and RNS (reactive nitrogen species) forming phenoxy radicals [56]. Another interesting mechanism for the radical scavenging activity of polyphenols was revealed by Rise-Evans et al., which showed that phenolic acids can stabilize or relocate unpaired electrons, chelate transition metal ions, catalyse free radicals (oxidation reactions), and may act as oxidation inhibitors [60].

These in vitro experiments demonstrated that polyphenols from SE leaves extract have radical scavenging capacity resulting in a cytoprotective effect even at a low concentration of $5 \mathrm{ug} / \mathrm{mL}$. It is known that the use of lipid vesicles as carriers could help cell internalization through endocytosis of polyphenols [61]. Hence, the SE extract loaded into lipid vesicles could be considered a good method to improve polyphenol cell internalization.

\section{Conclusions}

A hydroalcoholic polyphenols extract from Sambucus ebulus leaves was prepared and characterized using total polyphenols content $(25.50 \pm 0.010 \mathrm{mg} \mathrm{GAE} / \mathrm{g}$ dry material), and radical scavenging activity using DPPH assay $\left(\mathrm{IC}_{50}=10.33 \pm 0.056 \mu \mathrm{g} / \mathrm{mL}\right)$ and reverse phase HPLC-PDA analysis, which showed the presence of chlorogenic acid (in the highest amount among the identified compounds), caffeic acid, rutin, and quercetin. 
SE leaves extract was further loaded into three types of lipid vesicles: liposomes, transfersomes and ethosomes, which were characterized through their entrapment efficiency, AFM, enhanced dark-field microscopy, SEM and DLS measurements. All prepared SE-loaded lipid vesicles showed good entrapment efficiency (in the range of 75-85\%) and good stability over three months when stored at $4{ }^{\circ} \mathrm{C}$. The microscopy investigation proved the nanosized lipid vesicles with a narrow size distribution, the smallest being liposomes that are more hydrophobic and less deformable than transfersomes and ethosomes, while the largest ones were ethosomes, which exhibited the highest entrapment efficiency.

Polyphenols from SE leaves extract had slower release kinetics when were loaded in lipid vesicles in PBS pH 7.4 than their solubilisation in the same environment.

It was shown a cytoprotective effect of Sambucus ebulus leaves extract free and loaded into lipid vesicles against hydrogen peroxide induced-toxicity on L-929 mouse fibroblasts cell line. However, a short treatment of only $1 \mathrm{~h}$ with SE extract did not exhibit a significant cytoprotective action on cells, it was required at least $12 \mathrm{~h}$ of pre-treatment before exposure to hydrogen peroxide solution.

These results suggest that lipid vesicles could be exploited as carriers for polyphenols for biomedical or cosmetic applications, but further investigations are needed.

Supplementary Materials: The following are available online at http://www.mdpi.com/2079-4991/10/1/56/s1, Figure S1: Influence of a single factor on entrapment efficiency of SE extract-loaded liposomes: PC/cholesterol ratio (A), evaporation temperature (B), stirring rate (C), SE extract amount (D); Figure S2: Influence of a single factor on entrapment efficiency of SE extract-loaded transfersomes: PC/sodium cholate ratio (A), evaporation temperature (B), stirring rate (C), SE extract amount (D); Figure S3: Influence of a single factor on entrapment efficiency of SE extract-loaded ethosomes: PC/SE extract ratio (A), water/ethanol ratio (B); Figure S4: SEM image of freeze dried SE extract-loaded liposomes; Figure S5: Enhanced color view 2D AFM of SE extract-loaded lipid vesicles: liposomes (A), transfersomes (B) and ethosomes (C); Figure S6: SEM images of SE extract loaded lipid vesicles dried in vacuum; Table S1: Standard HPLC phenolic compounds: retention time $(R T)$ and standard deviation (SD), maximum wavelength $(\lambda \max )$, calibration curve $y=a x+b$ and correlation coefficients $\left(R^{2}\right)$.

Author Contributions: Conceptualization, R.-D.P., G.N. (Gheorghe Nechifor) and D.B.; Investigation, R.-D.P., F.S., C.B., M.D., G.N. (Georgeta Neagu), M.S., M.A., M.M. and C.M.; Data analysis, R.-D.P., F.S., C.B., M.D., G.N. (Georgeta Neagu) M.S., M.A., M.M., C.M. and D.B.; Supervision, D.B.; Writing-original draft, R.-D.P., F.S., C.B., M.D. and G.N. (Georgeta Neagu); Writing-review \& editing, D.B. All authors have read and agreed to the published version of the manuscript.

Funding: This research has been financed by Ministery of Research and Innovation CNCS-UEFISCDI, project PN-III-P1-1.1-PD-2016-1756, ctr. 74/ 2018 and PN16410302. Dark-field microscopy on CytovivaR equipment were possible due to European Regional Development Fund through Competitiveness Operational Program 2014-2020, Priority axis 1, Project No. P_36_611, MySMIS code 107066, Innovative Technologies for Materials Quality Assurance in Health, Energy and Environmental-Center for Innovative Manufacturing Solutions of Smart Biomaterials and Biomedical Surfaces-INOVABIOMED.

Conflicts of Interest: The authors declare no conflict of interest.

\section{References}

1. Fabricant, D.S.; Farnsworth, N.R. The value of plants used in traditional medicine for drug discovery. Environ. Health Perspect. 2001, 109 (Suppl. S1), 69-75. [CrossRef] [PubMed]

2. Koehn, F.E.; Carter, G.T. The evolving role of natural products in drug discovery. Nat. Rev. Drug Discov. 2005, 4, 206-220. [CrossRef] [PubMed]

3. Vlachojannis, J.; Cameron, M.; Chrubasik, S. A systematic review on the sambuci fructus effect and efficacy profiles. Phytother. Res. 2010, 24, 1-8. [CrossRef] [PubMed]

4. Yesilada, E.; Gurbuz, I.; Toker, G. Anti-ulcerogenic activity and isolation of the active principles from Sambucus ebulus L. leaves. J. Ethnopharmacol. 2014, 153, 478-483. [CrossRef]

5. Bubulica, M.-V.; Chirigiu, L.; Popescu, M. Analysis of sterol compounds from Sambucus ebulus. Chem. Nat. Compd. 2012, 48, 520-521. [CrossRef]

6. Duymus ${ }_{s}$ H.G.; Goger, F.; Baser, K.H.C. In vitro antioxidant properties and anthocyanin compositions of elderberry extracts. Food Chem. 2014, 155, 112-119. [CrossRef]

7. Pieri, V.; Schwaiger, S.; Ellmerer, E.P.; Stuppner, H. Iridoid glycosides from the leaves of Sambucus ebulus. J. Nat. Prod. 2009, 72, 1798-1803. [CrossRef] 
8. Schwaiger, S.; Zeller, I.; Polzelbauer, P.; Frotschnig, S.; Laufer, G.; Messner, B.; Pieri, V.; Stuppner, H.; Bernhard, D. Identification and pharmacological characterization of the anti-inflammatory principal of the leaves of dwarf elder (Sambucus ebulus L.). J. Ethnopharmacol. 2010, 133, 704-709. [CrossRef]

9. Bakowska-Barczak, A.; Kolodziejczyk, P. Black currant polyphenols: Their storage stability and microencapsulation. Ind. Crop. Prod. 2011, 34, 1301-1309. [CrossRef]

10. Đorđević, V.; Balanc, B.; Belščak-Cvitanović, A.; Lević, S.; Trifković, K.; Kalušević, A.; Kostić, I.; Komes, D.; Bugarski, B. Trends in encapsulation technologies for delivery of food bioactive compounds. J. Food Eng. 2015, 7, 452-490. [CrossRef]

11. Faridi Esfanjani, A.F.; Jafari, S.M. Biopolymer nano-particles and natural nano-carriers for nano-encapsulation of phenolic compounds. Colloids Surf. B Biointerfaces 2016, 146, 532-543. [CrossRef] [PubMed]

12. Souguir, H.; Salaün, F.; Douillet, P.; Vroman, I.; Chatterjee, S. Nanoencapsulation of curcumin in polyurethane and polyurea shells by an emulsion diffusion method. Chem. Eng. J. 2013, 221, 133-145. [CrossRef]

13. Cui, H.; Zhang, C.; Li, C.; Lin, L. Preparation and antibacterial activity of Litsea cubeba essential oil/dandelion polysaccharide nanofiber. Ind. Crop. Prod. 2019, 140, 1117-1139. [CrossRef]

14. Zadegan, S.; Nourmohammadi, J.; Vahidi, B.; Haghighipour, N. An investigation into osteogenic differentiation effects of silk fibroin-nettle (Urtica dioica L.) nanofibers. Int. J. Biol. Macromol. 2019, 133, 795-803. [CrossRef]

15. Faridi Esfanjani, A.; Assadpour, E.; Mahdi Jafari, S. Improving the bioavailability of phenolic compounds by loading them within lipid-based nanocarriers. Trends Food Sci. Technol. 2018, 76, 56-66. [CrossRef]

16. Faridi Esfanjani, A.F.; Jafari, S.M.; Assadpour, E. Preparation of a multiple emulsion based on pectin-whey protein complex for encapsulation of saffron extract nanodroplets. Food Chem. 2017, 221, 1962-1969. [CrossRef]

17. Müller, R.H.; Radtke, M.; Wissing, S.A. Solid lipid nanoparticles (SLN) and nanostructured lipid carriers (NLC) in cosmetic and dermatological preparations. Adv. Drug Deliv. Rev. 2002, 54, 131-155. [CrossRef]

18. Aditya, N.P.; Macedo, A.S.; Doktorovova, S.; Souto, E.B.; Kim, S.; Chang, P.S.; Ko, S. Development and evaluation of lipid nanocarriers for quercetin delivery: A comparative study of solid lipid nanoparticles (SLN), nanostructured lipid carriers (NLC), and lipid nanoemulsions (LNE). Food Sci. Technol. 2014, 59, 115-121. [CrossRef]

19. Athmouni, K.; Belhaj, D.; Gammoudi, S.; El Feki, A.; Ayadi, H. Nano-encapsulation using macrocyclic carbohydrate polymers ( $\beta$-cyclodextrins) of Periploca angustifolia extract: Physical stability and protective effect against cadmium-induced alterations in HepG2 cells. Int. J. Biol. Macromol. 2019, 125, 711-720. [CrossRef]

20. Simionato, I.; Domingues, F.; Nerín, C.; Silva, F. Encapsulation of cinnamon oil in cyclodextrin nanosponges and their potential use for antimicrobial food packaging. Food Chem. Toxicol. 2019, 132, 1-9. [CrossRef]

21. Trinh, L.H.; Takzare, A.; Ghafoor, D.; Siddiqi, A.F.; Ravali, S.; Shalbaf, M.; Bakhtiar, M. Trachyspermum copticum essential oil incorporated niosome for cancer treatment. J. Drug Deliv. Sci. Technol. 2019, 52, 818-824. [CrossRef]

22. Fidan-Yardimci, M.; Akay, S.; Sharifi, F.; Sevimli-Gur, C.; Ongen, G.; Yesil-Celiktas, O. A novel niosome formulation for encapsulation of anthocyanins and modelling intestinal transport. Food Chem. 2019, 293, 57-65. [CrossRef] [PubMed]

23. Odeberg, J.M.; Lignell, A.; Pettersson, A.; Hoglund, P. Oral bioavailability of the antioxidant astaxanthin on humans is enhanced by incorporation of lipid based formulations. Eur. J. Pharm. Sci. 2003, 19, 299-304. [CrossRef]

24. Chauhan, N.S.; Gowtham, R.; Gopalkrishna, B. Phytosomes: A potential phyto-phospholipid carriers for herbal drug delivery. J. Pharm. Res. 2009, 2, 1267-1270.

25. Baomiao, D.; Xiaoming, Z.; Khizar, H.; Shiqin, X.; Chengsheng, J.; Mingyong, X.; Chengmei, L. Preparation, characterization and the stability of ferrous glycinate nanoliposomes. J. Food Eng. 2011, 102, 202-208. [CrossRef]

26. Zhou, Z.; Xiao, J.; Fan, H.X.; Yu, Y.; He, R.-R.; Feng, X.-L.; Kurihara, H.; So, K.-F.; Yao, X.-S.; Gao, H. Polyphenols from wolfberry and their bioactivities. Food Chem. 2016, 214. [CrossRef]

27. Bangham, A.D.; Horne, R.W. Negative staining of phospholipids and their structural modification by surface active agents as observed in the electron microscope. J. Mol. Biol. 1964, 8, 660-668. [CrossRef] 
28. Cevc, G.; Blume, G. New, highly efficient formulation of diclofenac for the topical, transdermal administration in ultradeformable drug carriers, Transfersomes. BBA-Biomembr. 2001, 1514, 191-205. [CrossRef]

29. Touitou, E.; Dayan, N.; Bergelson, L.; Godin, B.; Eliaz, M. Ethosomes-novel vesicular carriers for enhanced delivery: Characterization and skin penetration properties. J. Control. Release 2000, 65, 403-418. [CrossRef]

30. Stanciuc, N.; Oancea, A.M.; Aprodu, I.; Turturica, M.; Barbu, V.; Ionita, E.; Rapeanu, G.; Bahrim, G. Investigations on binding mechanism of bioactives from elderberry (Sambucus nigra L.) by whey proteins for efficient microencapsulation. J. Food Eng. 2017, 223, 197-207. [CrossRef]

31. Sobieralska, M.; Kurek, M.A. Beta-Glucan as Wall Material in Encapsulation of Elderberry (Sambucus nigra) Extract. Plant Foods Hum. Nutr. 2019, 74, 334-341. [CrossRef] [PubMed]

32. Bryła, A.; Lewandowicz, G.; Juzwa, W. Encapsulation of elderberry extract into phospholipid nanoparticles. J. Food Eng. 2015, 167, 189-195. [CrossRef]

33. Jabbari, M.; Daneshfard, B.; Emtiazy, M.; Khiveh, A.; Hashempur, M.H. Biological Effects and Clinical Applications of Dwarf Elder (Sambucus ebulus L.): A Review. J. Evid.-Based Complement. Altern. Med. 2017, 22, 996-1001. [CrossRef] [PubMed]

34. Singleton, V.L.; Orthofer, R.R.; Lamuela-Raventos, R.M. Analysis of total phenols and other oxidation substrates and antioxidants by means of Folin-Ciocalteu reagent. Methods Enzymol. 1999, 299, 152-178. [CrossRef]

35. Nicoletti, I.; Bello, C.; De Rosii, A.; Corradini, D. Identification and quatification of phenolic compounds in grapes by HPLC-PDA-ESI-MS on a semimicro separation scale. J. Agric. Food Chem. 2008, 56, 8801-8808. [CrossRef] [PubMed]

36. Sanchez-Moreno, C.; Larrauri, J.A.; Saura-Calixto, F. A procedure to measure the antiradical efficiency of polyphenols. J. Agric. Food Chem. 1998, 76, 270-276. [CrossRef]

37. Feizbakhsh, A.; Pazoki, H.; Ebrahimzadeh, M.A. Sambucus ebulus, introduction to mechanism of action; a chemical viewpoint. Pharmacologyonline 2010, 1, 16-22.

38. Castangia, I.; Caddeo, C.; Manca, M.L.; Casu, L.; Catalan Latorre, A.; Díez-Sales, O.; Ruiz-Saurí, A.; Bacchetta, G.; Fadda, A.M.; Manconi, M. Delivery of liquorice extract by liposomes and hyalurosomes to protect the skin against oxidative stress injuries. Carbohydr. Polym. 2015, 134, 657-663. [CrossRef]

39. Gharib, R.; Amal Najjar, A.; Auezova, L.; Catherine Charcosset, C.; Greige-Gerges, H. Interaction of selected phenylpropenes with dipalmitoylphosphatidylcholine membrane and their relevance to antibacterial activity. J. Membr. Biol. 2017, 250, 259-271. [CrossRef]

40. Gibis, M.; Vogt, E.; Weiss, J. Encapsulation of polyphenolic grape seed extract in polymer-coated liposomes. Food Funct. 2012, 3, 246-254. [CrossRef]

41. Gibis, M.; Rahn, N.; Weiss, J. Physical and oxidative stability of uncoated and chitosan-coated liposomes containing grape seed extract. Pharmaceutics 2013, 5, 421-433. [CrossRef] [PubMed]

42. Soon, S.K.; Sun, Y.K.; Bong, J.K.; Kyeong, J.K.; Geun, Y.N.; Na, R.I.; Ji, W.L.; Ji, H.H.; Junoh, K.; Soo, N.P. Cell penetrating peptide conjugated liposomes as transdermal delivery system of Polygonum aviculare L. extract. Int. J. Pharm. 2015, 483, 26-37. [CrossRef]

43. Maitani, Y.; Soeda, H.; Junping, W.; Takayama, K. Modified ethanol injection method for liposomes containing beta-sitosterol beta-D-glucoside. J. Liposome Res. 2001, 11, 115-125. [CrossRef] [PubMed]

44. Detoni, C.B.; Cabral-Albuquerque, E.C.; Hohlemweger, S.V.; Sampaio, C.; Barros, T.F.; Velozo, E.S. Essential oil from Zanthoxylum tingoassuiba loaded in to multilamellar liposomes useful as antimicrobial agents. J. Microencapsul. 2009, 26, 684-691. [CrossRef] [PubMed]

45. Detoni, C.B.; de Oliveira, D.M.; Santo, I.E.; Santo, I.E.; Pedro, A.S.; El-Bacha, R.; da Silva Velozo, E.; Ferreira, D.; Sarmento, B.; de Magalhães Cabral-Albuquerque, E.C. Evaluation of thermal-oxidative stability and antiglioma activity of Zanthoxylum tingoassuiba essential oil entrapped into multi- and unilamellar liposomes. J. Liposome Res. 2012, 22, 1-7. [CrossRef]

46. Makino, K.; Yamada, T.; Kimura, M.; Oka, T.; Oshima, H. Temperature- and ionic strength-induced conformational changes in the lipid head group region of liposomes as suggested by zeta potential data. Biophys. Chem. 1991, 41, 175-183. [CrossRef]

47. Sinico, C.; De Logu, A.; Lai, F.; Valenti, D.; Manconi, M.; Loy, G.; Bonsignore, L.; Fadda, A.M. Liposomal incorporation of Artemisia arborescens L. essential oil and in vitro antiviral activity. Eur. J. Pharm. Biopharm. 2005, 59, 161-168. [CrossRef] 
48. Fang, J.Y.; Hong, C.T.; Chiu, W.T.; Wang, Y.Y. Effect of liposomes and niosomes on skin permeation of enoxacin. Int. J. Pharm. 2001, 219, 61-72. [CrossRef]

49. Mohammed, A.R.; Weston, N.; Coombes, A.G.; Fitzgerald, M.; Perrie, Y. Liposome formulation of poorly water soluble drugs: Optimisation of drug loading and ESEM analysis of stability. Int. J. Pharm. 2004, 285, 23-34. [CrossRef]

50. Gupta, A.; Aggarwal, G.; Singla, S.; Arora, R. Transfersomes: A Novel Vesicular Carrier for Enhanced Transdermal Delivery of Sertraline: Development, Characterization, and Performance Evaluation. Sci. Pharm. 2012, 80, 1061-1080. [CrossRef]

51. Ignacio, M.; Chubynsky, M.V.; Slater, G.W. Interpreting the Weibull fitting parameters for diffusion-controlled release data. Phys. A 2017, 486, 486-496. [CrossRef]

52. Martínez, E.; Villalobos, R.; Sánchez, M.; Cruz, J.; Ganem, A.; Melgoza, L.M. Monte Carlo simulations for the study of drug release from cylindrical matrix systems with an inert nucleus. Int. J. Pharm. 2009, 369, 38-46. [CrossRef] [PubMed]

53. Siepmann, J.; Peppas, N.A. Modeling of drug release from delivery systems based on hydroxypropyl methylcellulose (HPMC). Adv. Drug Deliv. Rev. 2012, 64, 163-174. [CrossRef]

54. Gibis, M.; Zeeb, B.; Weiss, J. Formation, characterization, and stability of encapsulated hibiscus extract in multilayered liposomes. Food Hydrocoll. 2014, 38, 28-39. [CrossRef]

55. Gibis, M.; Ruedt, C.; Weiss, J. In vitro release of grape-seed polyphenols encapsulated from uncoated and chitosan-coated liposomes. Food Res. Int. 2016, 88, 105-113. [CrossRef]

56. Pereira, D.M.; Valento, P.; Pereira, J.A.; Andrad, P.B. Phenolics: From chemistry to biology. Molecules 2009, 14, 2202-2211. [CrossRef]

57. Vinson, J.A.; Su, X.; Zubik, L.; Bose, P. Phenol antioxidant quantity and quality in foods: Fruits. J. Agric. Food Chem. 2001, 49, 5315-5321. [CrossRef]

58. Halliwell, B. Are polyphenols antioxidants or pro-oxidants? What do we learn from cell culture and in vivo studies? Arch. Biochem. Biophys. 2008, 476, 107-112. [CrossRef]

59. Forman, H.J.; Davies, K.J.A.; Ursini, F. How do nutritional antioxidants really work: Nucleophilic tone and para-hormesis versus free radical scavenging in vivo. Free Radic. Biol. Med. 2014, 66, 24-35. [CrossRef]

60. Rice-Evans, C.; Miller, N.; Paganga, G. Antioxidant properties of phenolic compounds. Trends Plant Sci. 1997, 2, 1529. [CrossRef]

61. Turkez, H.; Sozio, P.; Geyikoglu, F.; Tatar, A.; Hacimuftuoglu, A.; Di Stefano, A. Cell Neuroprotective effects of farnesene against hydrogen peroxide-induced neurotoxicity in vitro. Mol. Neurobiol. 2014, 34, 101-111. [CrossRef] [PubMed]

(C) 2019 by the authors. Licensee MDPI, Basel, Switzerland. This article is an open access article distributed under the terms and conditions of the Creative Commons Attribution (CC BY) license (http://creativecommons.org/licenses/by/4.0/). 